\title{
Medication Effectiveness with the Use of Tumor Necrosis Factor Inhibitors Among Texas Medicaid Patients Diagnosed with Rheumatoid Arthritis
}

\author{
Abiola Oladapo, PhD; Jamie C. Barner, PhD; Kenneth A. Lawson, PhD; Suzanne Novak, MD, PhD; \\ Karen L. Rascati, PhD; Kristin M. Richards, PhD; and David J. Harrison, PhD
}

\section{ABSTRACT}

BACKGROUND: Adalimumab (Humira [ADA]), etanercept (Enbrel [ETN]), and infliximab (Remicade [IFX]) are tumor necrosis factor (TNF) inhibitors indicated for the treatment of a variety of disorders. While their effectiveness has not been directly compared in a clinical trial, results from the majority of the indirect treatment comparisons suggest comparable efficacy and safety profiles. However, these TNF inhibitor agents differ in administration method and dosing flexibility, which may result in differences in medication use profiles (e.g., adherence, persistence, discontinuation, dose escalation, and switching to a new biologic rheumatoid arthritis drug) and effectiveness in clinical practice.

OBJECTIVE: To estimate the effectiveness of ADA, ETN, and IFX in patients with rheumatoid arthritis (RA) using a validated, claims-based algorithm designed for large retrospective databases.

METHODS: Adult (aged 18-63 years) patients diagnosed with RA, and receiving ADA, ETN, or IFX, and insured by Texas Medicaid were included. The index date was the date of the first prescription claim for ADA or ETN or infusion record for IFX with no claim or infusion record of a biologic drug in the preceding 6 months (i.e., biologic naïve). The study time frame was from July 2003 to August 2011, and prescription and medical claims for each subject were analyzed over an 18-month period (6 months pre- and 12 months post-index). Based on a RA medication effectiveness algorithm (Curtis et al. 2011), a RA medication was classified as effective if each of the following 6 criteria were met: (1) high medication adherence (i.e., medication possession ratio [MPR] $\geq 80 \%$, defined as the sum of days' supply for all fills or infusions divided by the number of days in the study period);

(2) no switching to (or addition of) new biologic RA drugs; (3) no addition of new nonbiologic RA drugs; (4) no increase in dose or frequency of administration of the RA medication currently evaluated; (5) no more than 1 glucocorticoid (GC) joint injection; and (6) no increase in dose of a concurrent oral GC. Propensity score (PS) matching was employed, and paired tests (i.e., McNemar's) and multivariate conditional logistic regression analysis were used to compare groups. Demographic (i.e., age, gender, race) and clinical (i.e., use of nonbiologic disease-modifying antirheumatic drugs [DMARDs], pain medication use, GC medication use, RA-related and nonRA-related health care visits [i.e., ambulatory and inpatient visits], number of nonstudy RA medications, and comorbidity index) characteristics, including total health care utilization cost at baseline, served as study covariates.

RESULTS: After PS matching, 822 patients ( $n=274$ per group) were included. The majority of the sample $(69.2 \%)$ was between $45-63$ years, female (88\%), and Hispanic (53.7\%). Results for each TNF inhibitor differed significantly for 2 of the 6 effectiveness criteria (i.e., medication adherence and dose escalation). A significantly higher proportion of patients on IFX were adherent compared with patients on ETN or ADA (38.3\% vs. $16.4 \%$ and $21.2 \%, P<0.0001$ for both). Adherence rates between ETN and ADA were not significantly different. A significantly higher $(P<0.0001)$ proportion of patients on ETN had no dose escalation compared with patients on ADA or IFX (98.2\% vs. $88.7 \%$ and $80.3 \%, P<0.0001)$. Dose escalation rate was also significantly lower $(P=0.0106)$ for ADA compared with IFX. The multivariate conditional logistic regression analysis indicated no significant difference in overall effectiveness using the claims-based algorithm among the 3 TNF inhibitors nor any significant relationship between effectiveness and the study covariates.

CONCLUSION: The study results suggest that when using a medication effectiveness algorithm, IFX, ETN, and ADA have comparable effectiveness in patients with RA. Patient adherence to therapy may be higher if given IFX, and patients who receive ETN are less likely to have a dose escalation. J Manag Care Pharm. 2014;20(7):657-67

Copyright $\odot 2014$, Academy of Managed Care Pharmacy. All rights reserved.

\section{What is already known about this subject}

Clinical trials that directly compare the efficacy of adalimumab (ADA), etanercept (ETN), and infliximab (IFX) are lacking. Results from the majority of the indirect treatment comparison studies suggest comparable efficacy and safety profiles.

Differences in the method of administration and flexibility of dosing of these agents may result in differences in medication use profiles (e.g., adherence, persistence, discontinuation, dose escalation, and switching to a new biologic rheumatoid arthritis [RA] drug) and effectiveness in real-life clinical settings.

\section{What this study adds}

The present study estimated the effectiveness of ADA, ETN, and IFX among RA patients using a validated, claims-based algorithm designed for large retrospective databases.

Study results indicated comparable effectiveness among the study medications. 


\section{Medication Effectiveness with the Use of Tumor Necrosis Factor Inhibitors Among Texas Medicaid Patients Diagnosed with Rheumatoid Arthritis}

$\mathrm{R}$ heumatoid arthritis (RA) is an autoimmune disease characterized by chronic inflammation of the joints. ${ }^{1}$ RA is a leading cause of disability and affects about $1 \%$ of the adult U.S. population with a higher prevalence, incidence, and lifetime risk in women compared with men., ${ }^{2,3}$ The direct medical cost related to RA management in the United States has been estimated to exceed $\$ 4$ billion annually. ${ }^{4} \mathrm{RA}$ negatively impacts patients' health-related quality of life, causing significant joint pain, disability, and limited mobility. ${ }^{3}$ It has also been associated with increased mortality, since it predisposes patients to increased risk for cardiovascular-related diseases, cancer, infections, and mental health conditions. ${ }^{3}$ Overall, RA contributes to a reduction in lifespan by 5 to 10 years. ${ }^{3}$ Although the etiology of RA remains unknown, it has been speculated that it may result from an interaction between environmental exposure and genetic factors. Risk factors for RA include age, being of female sex, presence of specific human leukocyte antigen (HLA) class II genotypes (e.g., HLA-DR4, HLA-DRB1 alleles), tobacco use, dietary factors, reproductive hormonal exposures (e.g., oral contraceptives, hormone replacement therapy) as well as exposures to microbial agents (e.g., Escherichia coli, proteus species, cytomegalovirus, and Epstein-Barr virus) and their products (heat-shock proteins). ${ }^{3}$

Current treatment goals focus on slowing or stopping the progression (i.e., inducing remission) of the disease. Among the available treatment options, the tumor necrosis factor (TNF) inhibitors have been shown through randomized clinical trials (RCTs) to significantly improve patients' symptoms as well as inhibit future joint damage. ${ }^{5-9}$ TNF inhibitors have been recommended for patients who failed to achieve remission or a satisfactory response following treatment with traditional or nonbiologic disease-modifying antirheumatic drugs (DMARDs; e.g., methotrexate). They have been found to be even more effective when used in combination with traditional DMARDs. ${ }^{3,6-11}$ Among the available TNF inhibitors, 3 agentsadalimumab (Humira [ADA]), etanercept (Enbrel [ETN]), and infliximab (Remicade [IFX])—have been extensively studied and are the most commonly used. While no clinical trial has been conducted to directly compare the 3 agents, results from the majority of the indirect treatment comparison studies suggest that these agents have comparable efficacy and safety profiles. ${ }^{12-17}$ However, the drugs differ in their methods of administration and flexibility of dosing (ADA and ETN administered subcutaneously and IFX administered intravenously), ${ }^{18-20}$ which may result in differences in medication use profiles (e.g., adherence, persistence, discontinuation, switching, and dose escalation) and effectiveness in real-life clinical settings. In the face of limited health care resources, availability of information on clinical effectiveness will enhance the decision-making process in the management of RA patients.

Prospective data from registries can be used to compare the effectiveness of these agents among RA patients, since they provide detailed information on diagnosis, disease activity, and treatment. ${ }^{21}$ However, many registries have a limited sample size and incomplete information on patient comorbidities and other medications patients might be taking. ${ }^{21}$ Retrospective databases (administrative claims data) typically have larger sample sizes, complete prescription drug data, and greater generalizability, ${ }^{22}$ but they lack clinical information regarding disease severity and disability status. ${ }^{23}$ Curtis et al. (2011) developed an algorithm to serve as proxy for evaluating the clinical effectiveness of RA medications using administrative claims data. ${ }^{24}$ Based on this algorithm, a RA medication is classified as effective if it requires no increase in its dose or dosing frequency, no switching to (or addition of) new biologic or nonbiologic RA drugs, no more than 1 glucocorticoid (GC) joint injection, no increase in dose of a concurrent oral GC, and has high patient medication adherence. Although this algorithm has been validated, limited information exists in the literature regarding its use..$^{24,25}$ The objective of this study was to estimate the effectiveness of ADA, ETN, and IFX among RA patients using the comparative effectiveness algorithm designed by Curtis et al. for large retrospective databases. ${ }^{24}$

FIGURE 1 Data Extraction and Subject Identification Period

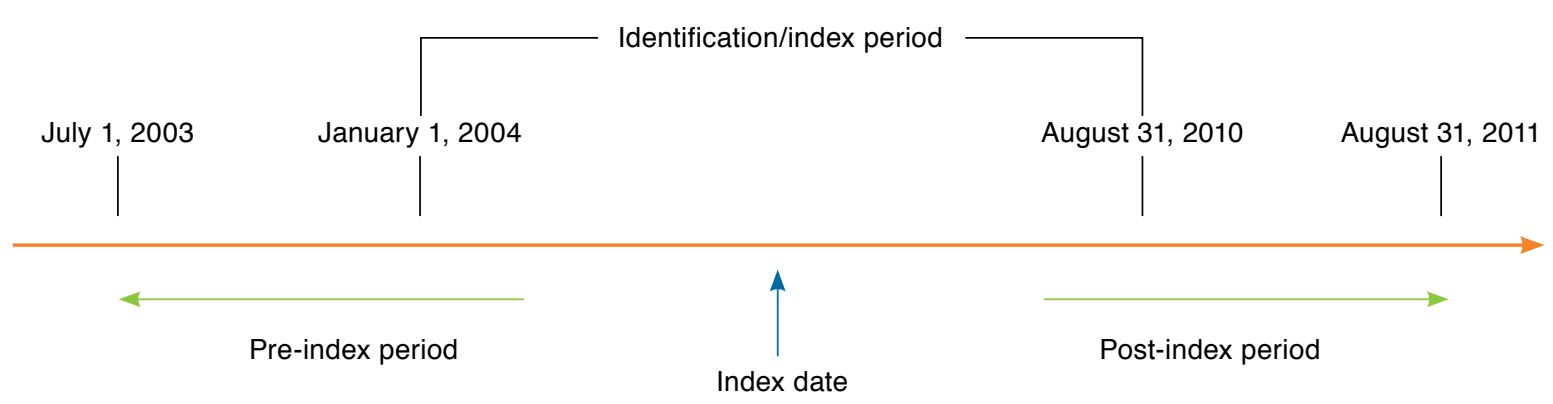




\begin{tabular}{|c|c|}
\hline Criteria & Details \\
\hline \multirow[t]{2}{*}{ Adherence (high) } & $\geq 80 \%$ MPR for patients on ADA or ETN \\
\hline & $\begin{array}{l}\text { For IFX, patients must have received at least the number of infusions expected between the index and outcome } \\
\text { visit dates to conform to a schedule of } 0,2,6 \text {, and } 14 \text { weeks and every } 8 \text { weeks thereafter }\end{array}$ \\
\hline No switching or adding biologics & Between index and last follow-up date (last prescription) \\
\hline $\begin{array}{l}\text { No additions of new nonbiologic DMARDs } \\
\text { (MTX, SSZ, LEF, HCQ) }\end{array}$ & $\begin{array}{l}\text { Between index and last follow-up date (last prescription) patients cannot initiate new nonbiologic DMARD } \\
\text { unless they received a prescription in the pre-index period }\end{array}$ \\
\hline \multirow[t]{2}{*}{ No increase in biologic dose or frequency } & No dose escalation of ETN to $50 \mathrm{mg}$ twice weekly or ADA to $40 \mathrm{mg}$ weekly. \\
\hline & $\begin{array}{l}\text { IFX end dose-IFX start dose }<100 \mathrm{mg} \text {, number of infusions must be within } 120 \% \text { of expected based on } 0-, 2-\text {, } \\
6 \text {-, and } 8 \text {-week schedule }\end{array}$ \\
\hline No more than 1 GC joint injection & $\begin{array}{l}\text { No more than } 1 \text { GC injection on } 1 \text { calendar day between index date }+90 \text { days and last follow-up date (last pre- } \\
\text { scription) }\end{array}$ \\
\hline \multirow[t]{2}{*}{ No increase in dose of oral GC } & $\begin{array}{l}\text { If no oral GC during pre-index period, patients cannot have }>30 \text { days oral GC between index date }+90 \text { days } \\
\text { and last follow-up date (last prescription) }\end{array}$ \\
\hline & $\begin{array}{l}\text { If patients received oral GC during pre-index period, cumulative GC dose } 6 \text { months prior to last follow-up date } \\
\text { must be within } 120 \% \text { of the cumulative oral GC dose in the pre-index period }\end{array}$ \\
\hline Effectiveness & $1=$ Yes (met all 6 criteria above); $0=$ No (did not meet all of the above criteria) \\
\hline \multicolumn{2}{|c|}{$\begin{array}{l}\text { Adapted from: Curtis JR, Baddley JW, Yang S, et al. Derivation and preliminary validation of an administrative claims-based algorithm for the effectiveness of medications } \\
\text { for rheumatoid arthritis. } 24\end{array}$} \\
\hline \multicolumn{2}{|c|}{$\begin{array}{l}\text { ADA = adalimumab; } D M A R D s=\text { disease-modifying antirheumatic drugs; } E T N=\text { etanercept } ; G C=\text { glucocorticoid; HCQ =hydroxychloroquine; IFX=infliximab; } L E F=l e f l u- \\
\text { nomide; } m g=\text { milligram; } M P R=\text { medication possession ratio, which was defined as the sum of days' supply for all fills divided by the number of days in the study period; } \\
\text { MTX=methotrexate; } S S Z=\text { sulfasalazine. }\end{array}$} \\
\hline
\end{tabular}

\section{Methods}

\section{Data Source}

This was a retrospective study involving de-identified demographic, medical, and prescription claims records of Texas Medicaid patients with RA between the ages of 18 and 63 years on TNF inhibitors (ADA, ETN, and IFX) between July 2003 and August 2011. Subjects were identified during the index period from January 1, 2004, to August 31, 2010. The index date was defined as the date within the identification period (Figure 1) when the patients had their first claim fill or infusion for any of the study TNF inhibitors without any fills or infusion during the prior 6 months (Figure 1). Prescription claims and infusion records for each subject were analyzed over an 18-month study period (i.e., the 6-month pre-index and 12 -month post-index periods).

Information extracted from the Texas Medicaid medical and prescription claims files included the following: de-identified unique patient identification numbers, gender, race/ethnicity, enrollment dates, International Classification of Diseases, Ninth Revision, Clinical Modification (ICD-9-CM) diagnostic codes, Healthcare Common Procedure Coding System (HCPCS) codes, dates and costs of medical and prescription services, medication quantity, medication days of supply, National Drug Code (NDC), Generic Sequencing Number (GCN), and American Hospital Formulary Service (AHFS) number. The study protocol and data use were approved by The University of Texas at Austin Institutional Review Board and by the Texas Health and Human Services Commission.

\section{Inclusion and Exclusion Criteria}

Texas Medicaid recipients who met the following eligibility criteria were included in the study: (a) adults between the ages of 18 and 63 years at the index date; (b) continuously enrolled with Texas Medicaid for at least 6 months before and 12 months after the index date; (c) have a diagnosis for RA in the 6-month pre-index period (ICD-9-CM code 714.0x) based on the medical claims record; (d) have no claim nor received an infusion for a biologic agent (i.e., abatacept [Orencia], adalimumab [Humira], anakinra [Kineret], certolizumab pegol [Cimza], etanercept [Enbrel], golimumab [Simponi], infliximab [Remicade], rituximab [Rituxan], and tocilizumab [Actemra]) indicated for RA within the 6-month pre-index period; and (e) have at least 1 claim or infusion for any of the study TNF inhibitors (ADA, ETN, and IFX) indicated for the treatment of RA.

Subjects with diagnosis for psoriasis (ICD-9-CM 696.1x); psoriatic arthritis (ICD-9-CM 696.0x); ankylosing spondylitis (ICD-9-CM 720.0x); ulcerative colitis (ICD-9-CM 556.0, 556.1, 556.2, 556.3, 556.5, 556.6, 556.8, or 556.9); Crohn's disease (ICD-9-CM 555.0x, 555.1x, 555.2x, 555.9x, 565.1x, or 569.81); juvenile idiopathic arthritis (ICD-9-CM 714.3x); non-Hodgkin's lymphoma (ICD-9-CM 200.xx or 202.xx); or chronic lymphocytic leukemia (ICD-9-CM 204.1x) were excluded, since the TNF inhibitors or other biologics used to treat RA are also used to treat these indications. The age range was limited to a maximum of 63 years to minimize the chance of including patients with dual eligibility status (i.e., Medicaid and Medicare). 


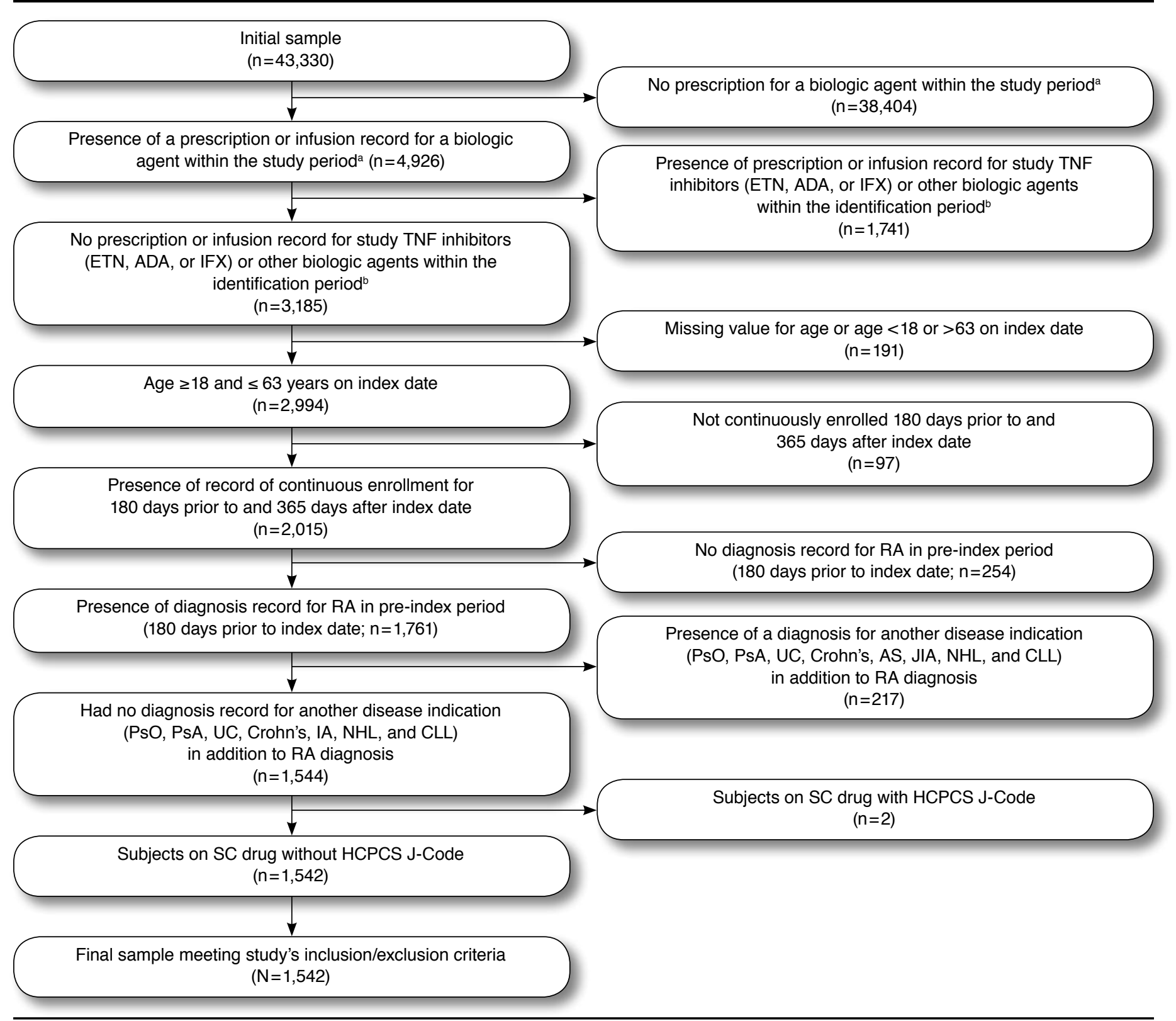

ajuly 1, 2003, to August 31, 2011.

bJanuary 1, 2004, to August 31, 2010.

$A D A=$ adalimumab; $A S=$ ankylosing spondylitis; $C L L=$ chronic lymphocytic leukemia; Crohn's=Crohn's disease; ETN=etanercept; HCPCS = Healthcare Common Procedure Coding System; IFX=infliximab; JIA = juvenile idiopathic arthritis; $N H L=$ non-Hodgkin's lymphoma; PsA = psoriatic arthritis; PsO=plaque psoriasis; $R A=$ rheumatoid arthritis; $S C=$ subcutaneous; $T N F=$ tumor necrosis factor; $U C=$ ulcerative colitis.

\section{Study End Point Assessment}

The primary end point was RA medication effectiveness, and this was determined by the Curtis et al. algorithm. ${ }^{24}$ Based on the algorithm, a RA medication was classified as effective in a particular patient if all the of following criteria were met:
(1) high medication adherence (i.e., medication possession ratio (MPR) $\geq 80 \%$, calculated as the sum of days' supply for all fills or infusions divided by the number of days in the study period); (2) no switching to (or addition of) new biologic RA drugs; (3) no addition of new nonbiologic drugs; (4) no increase 


\section{TABLE 2 Comparison of Baseline Characteristics by Type of TNF Inhibitor (Unmatched Population)}

\begin{tabular}{|c|c|c|c|c|}
\hline & ETN $(\mathrm{N}=578)$ & ADA $(\mathrm{N}=401)$ & IFX $(\mathrm{N}=563)$ & $P$ Value \\
\hline Age, mean $( \pm S D)^{a}$ & $49.7( \pm 10.0)$ & $50.3( \pm 10.0)$ & $50.8( \pm 9.3)$ & 0.1761 \\
\hline Female $(\%)^{b}$ & 89.6 & 89.0 & 87.6 & 0.5345 \\
\hline Race/ethnicity (\%) ${ }^{b}$ & & & & 0.8320 \\
\hline Hispanics & 53.5 & 53.6 & 54.7 & \\
\hline Caucasians & 26.6 & 26.9 & 28.1 & \\
\hline African Americans & 10.4 & 11.5 & 10.1 & \\
\hline Others & 9.5 & 8.0 & 7.1 & \\
\hline DMARD utilization (\%)b & 73.4 & 75.1 & 62.0 & $<0.0001$ \\
\hline Glucocorticoid utilization (\%)b & 49.7 & 52.9 & 29.0 & $<0.0001$ \\
\hline$\underline{\text { Pain medication }(\%)^{\mathrm{b}}}$ & 81.5 & 78.6 & 56.7 & $<0.0001$ \\
\hline Total number of nonstudy RA-related medications, mean $( \pm$ SD)a & $2.7( \pm 1.4)^{\mathrm{c}}$ & $2.5( \pm 1.3)^{\mathrm{c}}$ & $1.9( \pm 1.5)$ & $<0.0001$ \\
\hline \multicolumn{5}{|l|}{ Charlson Comorbidity Index ${ }^{\mathrm{d}}$} \\
\hline Median & $1.0^{\mathrm{e}}$ & $1.0^{\mathrm{e}}$ & 1.0 & 0.0045 \\
\hline Mean $( \pm$ SD) & $1.2( \pm 0.5)$ & $1.2( \pm 0.5)$ & $1.3( \pm 0.6)$ & \\
\hline Specialty of prescribing physician (\%)b,f & & & & $<0.0001$ \\
\hline Rheumatologist & 46.0 & 46.6 & 32.3 & \\
\hline General/family practice & 8.7 & 9.0 & 11.6 & \\
\hline Others & 45.3 & 44.5 & 39.1 & \\
\hline Missing & 0.0 & 0.0 & 17.1 & \\
\hline RA-related health care utilization ${ }^{\mathrm{d}, \mathrm{g}-\mathrm{i}}$ & & & & $<0.0001$ \\
\hline Median & 3.0 & 3.0 & 5.0 & \\
\hline Mean $( \pm$ SD) & $4.0( \pm 4.0)$ & $4.1( \pm 2.9)$ & $6.5( \pm 5.3)$ & \\
\hline Non-RA-related health care utilization ${ }^{\mathrm{d}, \mathrm{e}, \mathrm{i}}$ & & & & $<0.0001$ \\
\hline Median & $0.0^{\mathrm{e}}$ & $0.0^{e}$ & 1.0 & \\
\hline Mean $( \pm S D)$ & $0.7( \pm 1.3)$ & $0.8( \pm 1.2)$ & $1.4( \pm 1.9)$ & \\
\hline Pre-index total health care utilization costs $(\$) \mathrm{d}, \mathrm{e}, \mathrm{j}$ & & & & 0.0308 \\
\hline Median & $1,583^{\mathrm{e}}$ & $1,432^{\mathrm{e}}$ & 1,229 & \\
\hline Mean $( \pm$ SD) & $2,433( \pm 2,790)$ & $2,153( \pm 2,900)$ & $1,854( \pm 2,620)$ & \\
\hline \multicolumn{5}{|c|}{ 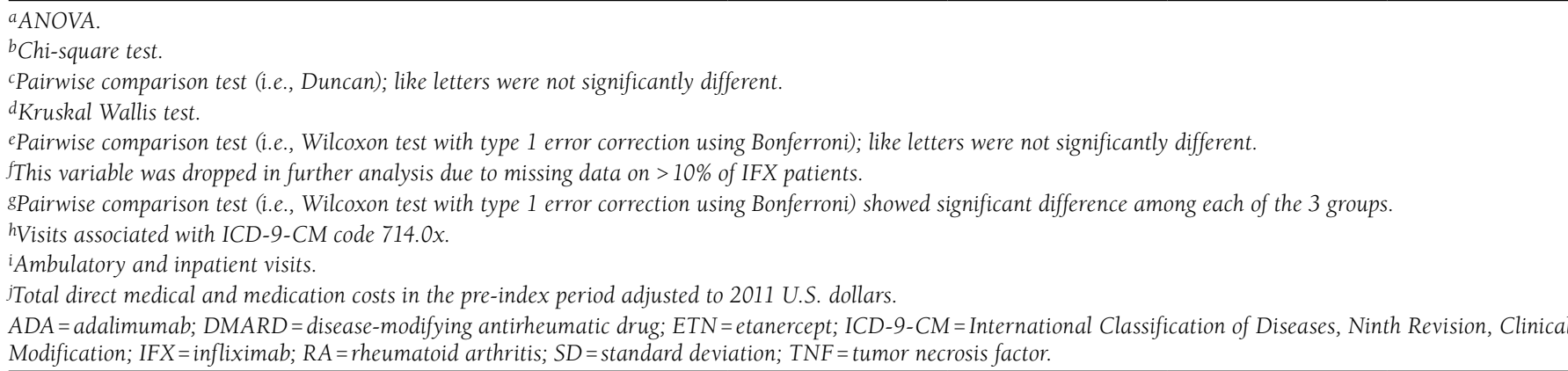 } \\
\hline
\end{tabular}

in dose or frequency of administration of the RA medication currently evaluated; (5) no more than 1 GC joint injection; and (6) no increase in dose of a concurrent oral GC. The description and implementation of each criterion is presented in Table 1.

\section{Study Covariates}

The covariates controlled for in the multivariate analysis included demographic factors (age, gender, race/ethnicity); pre-index use of other RA-related medications (i.e., nonsteroidal anti-inflammatory drugs, cyclooxygenase-2-inhibitors, narcotic analgesics, tramadol, corticosteroids, and nonbiologic DMARDS); total number of nonstudy RA-related medications at index; Charlson Comorbidity Index score (DartmouthManitoba); pre-index RA, non-RA-related outpatient visits; and total pre-index health care utilization cost. Total pre-index health care utilization costs were the direct costs (i.e., medical and medication costs combined). Texas Medicaid paid claims in the pre-index period for users of each of the study TNF inhibitors were adjusted to 2011 U.S. dollars (using the medical Consumer Price Index from the U.S. Bureau of Labor Statistics).

\section{Statistical Analyses}

All statistical analyses were performed using SAS for Windows, version 9.2 (SAS Institute, Cary, NC). All statistical analyses 
TABLE 3 Comparison of Baseline Characteristics by Type of TNF Inhibitor: Propensity-Score (Caliper) 3-Way Matched ${ }^{a}$

\begin{tabular}{|c|c|c|c|c|c|c|c|c|c|}
\hline & $\begin{array}{c}\text { ETN } \\
\mathrm{N}=274\end{array}$ & $\begin{array}{c}\text { ADA } \\
\mathrm{N}=274\end{array}$ & $\begin{array}{c}P \\
\text { Value }\end{array}$ & $\begin{array}{c}\text { ETN } \\
N=274\end{array}$ & $\begin{array}{c}\text { IFX } \\
\mathrm{N}=274\end{array}$ & $\begin{array}{c}P \\
\text { Value }\end{array}$ & $\begin{array}{c}\text { ADA } \\
\mathrm{N}=274\end{array}$ & $\begin{array}{c}\text { IFX } \\
\mathrm{N}=274\end{array}$ & $\begin{array}{c}P \\
\text { Value }\end{array}$ \\
\hline$\overline{\text { Age, mean }( \pm S D)^{b}}$ & $\begin{array}{c}49.1 \\
( \pm 9.8) \\
\end{array}$ & $\begin{array}{c}48.9 \\
( \pm 9.9) \\
\end{array}$ & 0.7638 & $\begin{array}{c}49.1 \\
( \pm 9.8) \\
\end{array}$ & $\begin{array}{c}48.7 \\
( \pm 9.6) \\
\end{array}$ & 0.6619 & $\begin{array}{c}48.9 \\
( \pm 9.9) \\
\end{array}$ & $\begin{array}{c}48.7 \\
( \pm 9.6) \\
\end{array}$ & 0.8710 \\
\hline Females (\%)c & 88.3 & 88.3 & 1.0000 & 88.3 & 87.2 & 0.7982 & 88.3 & 87.2 & 0.7914 \\
\hline Hispanics (\%)c & 54.0 & 52.6 & 0.7910 & 54.0 & 54.4 & 1.0000 & 52.6 & 54.4 & 0.7327 \\
\hline DMARD utilization (\%)c & 71.5 & 69.0 & 0.5341 & 71.5 & 75.9 & 0.2299 & 69.0 & 75.9 & 0.0558 \\
\hline Glucocorticoid utilization (\%)c & 43.8 & 45.3 & 0.7275 & 43.8 & 43.1 & 0.9022 & 45.3 & 43.1 & 0.5560 \\
\hline Pain medication $(\%)^{c}$ & 75.6 & 77.7 & 0.4885 & 75.6 & 80.3 & 0.1112 & 77.7 & 80.3 & 0.3916 \\
\hline $\begin{array}{l}\text { Total number of nonstudy RA-related } \\
\text { medications, mean }( \pm S D)^{b}\end{array}$ & $\begin{array}{c}2.4 \\
( \pm 1.3)\end{array}$ & $\begin{array}{c}2.4 \\
( \pm 1.3)\end{array}$ & 1.0000 & $\begin{array}{c}2.4 \\
( \pm 1.3)\end{array}$ & $\begin{array}{c}2.5 \\
( \pm 1.3)\end{array}$ & 0.3297 & $\begin{array}{c}2.4 \\
( \pm 1.3)\end{array}$ & $\begin{array}{c}2.5 \\
( \pm 1.3)\end{array}$ & 0.3174 \\
\hline Charlson Comorbidity Index, mean $( \pm S D)^{d}$ & $\begin{array}{c}1.2 \\
( \pm 0.5)\end{array}$ & $\begin{array}{c}1.2 \\
( \pm 0.5)\end{array}$ & 0.3679 & $\begin{array}{c}1.2 \\
( \pm 0.5)\end{array}$ & $\begin{array}{c}1.2 \\
( \pm 0.5)\end{array}$ & 0.5508 & $\begin{array}{c}1.2 \\
( \pm 0.5)\end{array}$ & $\begin{array}{l}1.2 \\
( \pm 0.5)\end{array}$ & 0.7994 \\
\hline RA-related health care resource utilization, ${ }^{\mathrm{d}-\mathrm{f}}$ median & 3.0 & 3.0 & \multirow[b]{2}{*}{0.5188} & 3.0 & 4.0 & \multirow[b]{2}{*}{0.0313} & 3.0 & 4.0 & \multirow[b]{2}{*}{0.0430} \\
\hline $\begin{array}{l}\text { RA-related health care resource utilization, } \\
\text { mean (SD) }\end{array}$ & $\begin{array}{c}4.1 \\
( \pm 3.3)\end{array}$ & $\begin{array}{c}4.1 \\
( \pm 2.7)\end{array}$ & & $\begin{array}{c}4.1 \\
( \pm 3.3)\end{array}$ & $\begin{array}{l}4.5 \\
( \pm 2.8)\end{array}$ & & $\begin{array}{c}4.1 \\
( \pm 2.7)\end{array}$ & $\begin{array}{c}4.5 \\
( \pm 2.8)\end{array}$ & \\
\hline $\begin{array}{l}\text { Non-RA-related health care resource utilization, }{ }^{\mathrm{d}-\mathrm{f}} \\
\text { median }\end{array}$ & 0.0 & 0.0 & \multirow{2}{*}{0.9650} & 0.0 & 0.0 & \multirow{2}{*}{0.1679} & 0.0 & 0.0 & \multirow{2}{*}{0.2472} \\
\hline $\begin{array}{l}\text { Non-RA-related health care resource utilization, } \\
\text { mean }( \pm \text { SD })\end{array}$ & $\begin{array}{c}0.8 \\
( \pm 1.3) \\
\end{array}$ & $\begin{array}{c}0.8 \\
( \pm 1.2) \\
\end{array}$ & & $\begin{array}{c}0.8 \\
( \pm 1.3) \\
\end{array}$ & $\begin{array}{c}0.9 \\
( \pm 1.3) \\
\end{array}$ & & $\begin{array}{c}0.8 \\
( \pm 1.2) \\
\end{array}$ & $\begin{array}{c}0.9 \\
( \pm 1.3)\end{array}$ & \\
\hline $\begin{array}{l}\text { Pre-index total health care resource } \\
\text { utilization cost }(\$), \mathrm{d}, \mathrm{g} \text { median }\end{array}$ & 1,477 & 1,376 & \multirow{2}{*}{0.7230} & 1,477 & 1,651 & \multirow{2}{*}{0.2383} & 1,376 & 1,651 & \multirow{2}{*}{0.0747} \\
\hline $\begin{array}{l}\text { Pre-index total health care resource utilization cost, } \\
\text { mean }( \pm S D)\end{array}$ & $\begin{array}{c}2,097 \\
( \pm 1,955)\end{array}$ & $\begin{array}{c}1,988 \\
( \pm 1,890)\end{array}$ & & $\begin{array}{c}2,097 \\
( \pm 1,955)\end{array}$ & $\begin{array}{c}2,210 \\
( \pm 2,152)\end{array}$ & & $\begin{array}{c}1,988 \\
( \pm 1,890)\end{array}$ & $\begin{array}{c}2,210 \\
( \pm 2,152)\end{array}$ & \\
\hline
\end{tabular}

Source of macros: Rassen JA, Doherty M, Huang W, Schneeweiss S. Pharmacoepidemiology toolbox. ${ }^{51}$

Article reference: Rassen JA, Shelat AA, Franklin JM, Glynn RJ, Solomon DH, Schneeweiss S. Matching by propensity score in cohort studies with three treatment groups. ${ }^{27}$ ${ }^{a}$ Caliper set at 0.05; Bonferroni correction was used to control for type 1 error due to multiple comparisons with a prior $P$ value set at $0.0167(0.05 / n$, where $n=3$, which is the number of comparisons).

${ }^{b}$ For the matched analysis, differences between matched pairs were evaluated using paired t test.

'For the matched analysis, differences between matched pairs were evaluated using McNemar's test.

${ }^{d}$ For the matched analysis, differences between matched pairs were evaluated using signed rank test.

eVisits associated with ICD-9-CM code 714.0x.

fAmbulatory and inpatient visits

sTotal direct medical and medication costs in the pre-index period adjusted to 2011 U.S. dollars.

$A D A=$ adalimumab; DMARD = disease-modifying antirheumatic drug; ETN=etanercept; ICD-9-CM = International Classification of Diseases, Ninth Revision, Clinical Modification; IFX=infliximab; $R A=$ rheumatoid arthritis; $S D=$ standard deviation; $T N F=$ tumor necrosis factor.

were two-tailed, and the significance level was set a priori at $P<0.05$. Power to detect significant differences was set at $80 \%$. Frequencies, skewness, kurtosis, and normality tests were computed to check for data abnormalities and normality distribution. Due to baseline differences in the covariates among the groups, a propensity score technique was used. ${ }^{26}$ Propensity scores (PS) were generated using multinomial logistic regression, and the study groups were matched using a 3-way match (nearest neighbor) with caliper set at 0.05. ${ }^{27}$ To determine if balance was achieved among the matched groups, differences between matched pairs were evaluated on each of the study covariates using the paired t-test or signed-rank test for continuous data and the McNemar's test for binary data. ${ }^{26}$ Bonferroni correction was used to control for type 1 error due to multiple comparisons. Descriptive statistics (mean, standard deviation, and frequency) were used to summarize baseline sociodemographics, clinical characteristics, and health care utilization cost patterns. Based on the type (categorical or continuous) and the distribution of data, appropriate statistical tests, which accounted for the matched nature of the final study sample, were conducted (e.g., McNemar's test for unadjusted pairwise comparison and conditional logistic regression for multivariate analysis).

\section{Results}

A total of 1,542 patients met the study criteria (Figure 2). At baseline, the 3 study groups presented with comparable demographic characteristics (i.e., age, gender, and race). However, at baseline, the ADA and ETN study groups differed in clinical characteristics from the IFX group, necessitating the need for a matching procedure to be conducted (Table 2). After PS matching, a final sample size of 822 patients ( $n=274$ per group) was obtained (Table 3), and there were no significant differences in clinical or demographic characteristics among the 3 study medications. At baseline, the majority of the matched sample (69.2\%) was between 45-63 years, female (88\%), and Hispanic (53.7\%). 


\section{TABLE 4 Baseline Summary Statistics for Matched Sample}

\begin{tabular}{|c|c|c|c|c|c|}
\hline Demographic \& Clinical Characteristics & $\mathrm{N}$ & $\%$ & Demographic \& Clinical Characteristics & $\mathrm{N}$ & $\%$ \\
\hline \multicolumn{3}{|l|}{ Age groups } & \multicolumn{3}{|l|}{ Types of oral glucocorticoids ${ }^{b}$} \\
\hline $18-34$ & 77 & 9.4 & Dexamethasone & 1 & 0.1 \\
\hline $35-44$ & 176 & 21.4 & Hydrocortisone & 0 & 0.0 \\
\hline $45-54$ & 292 & 35.5 & Methylprednisolone & 48 & 5.8 \\
\hline $55-63$ & 277 & 33.7 & Prednisolone & 0 & 0.0 \\
\hline Total & 822 & 100.0 & Prednisone & 301 & 36.6 \\
\hline \multicolumn{3}{|l|}{ Race/ethnicity } & Cortisone & 0 & 0.0 \\
\hline Caucasians & 226 & 27.5 & \multicolumn{3}{|l|}{ Types of glucocorticoid injections ${ }^{b}$} \\
\hline African Americans & 84 & 10.2 & Corticotrophin & 0 & 0.0 \\
\hline Hispanics & 441 & & Dexamethasone & 7 & 0.9 \\
\hline Others & 71 & 33.1 & Hydrocortisone & 0 & 0.0 \\
\hline Total & 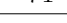 & 8.6 & Methylprednisolone & 25 & 3.0 \\
\hline & 822 & 100.0 & Prednisolone & 0 & 0.0 \\
\hline \multicolumn{3}{|l|}{ Gender } & Triamcinolone & 28 & 3.4 \\
\hline Female & 723 & 88.0 & \multicolumn{3}{|l|}{ Pain medications } \\
\hline Male & 99 & 12.0 & Yes & 640 & 77.9 \\
\hline Total & 822 & 100.0 & No & 182 & 22.1 \\
\hline \multicolumn{3}{|l|}{ Index TNF inhibitor } & Total & 822 & 100.0 \\
\hline Etanercept & 274 & 33.3 & \multicolumn{3}{|l|}{ Types of pain medications ${ }^{b}$} \\
\hline Adalimumab & 274 & 33.3 & NSAIDs & 212 & 25.8 \\
\hline Infliximab & 274 & 33.3 & COXIBs & 161 & 19.6 \\
\hline Total & 822 & $99.9^{\mathrm{a}}$ & Narcotic analgesics & 437 & 53.2 \\
\hline \multicolumn{3}{|l|}{ Pre-index DMARD utilization } & $\begin{array}{l}\text { Tramadol } \\
\text { Total number of nonstudy RA-related medicat }\end{array}$ & 138 & 16.8 \\
\hline Yes & 593 & 72.1 & 0 & 41 & 5.0 \\
\hline No & 229 & 27.9 & 1 & 157 & 19.1 \\
\hline Total & 822 & 100.0 & 2 & 242 & 29.4 \\
\hline \multicolumn{3}{|l|}{ Types of DMARD utilization ${ }^{b}$} & 3 & 218 & 26.5 \\
\hline Methotrexate & 478 & 58.2 & $\geq 4$ & 164 & 20.0 \\
\hline Leflunomide & 75 & 9.1 & Total & 822 & 100.0 \\
\hline Sulfasalazine & 79 & 9.6 & \multicolumn{3}{|l|}{ Charlson Comorbidity Index score } \\
\hline Hydroxychloroquine & 145 & 17.6 & $1-2$ & 798 & 97.1 \\
\hline Other DMARDsc & 6 & 0.7 & $\frac{\geq 3}{T 0 t a l}$ & 24 & 2.9 \\
\hline \multicolumn{3}{|l|}{ Pre-index glucocorticoid utilization } & $\begin{array}{l}\text { Total } \\
\text { Health care resource utilization (\# of visits) }\end{array}$ & 822 & 100.0 \\
\hline Yes & 362 & 44.0 & \multicolumn{3}{|l|}{ Health care resource utilization (\# of visits) } \\
\hline No & 460 & 56.0 & Non-RA-related ambulatory and inpatient care & 660 & 15.9 \\
\hline Total & 822 & 100.0 & Total visits & 4,149 & 100.0 \\
\hline \multicolumn{6}{|c|}{$\begin{array}{l}\text { aDoes not add up to } 100.0 \% \text { due to rounding error. } \\
{ }^{b} \text { Groups are not mutually exclusive because subjects may have used more than } 1 \text { medication. } \\
\text { 'Examples of other DMARDs: azathioprine, chloroquine, cyclophosphamide, cyclosporine, minocycline, and sodium aurothiomalate (gold). } \\
d^{d V i s i t s ~ a s s o c i a t e d ~ w i t h ~ I C D-9-C M ~ c o d e ~} 714.0 x \text {. } \\
\text { COXIB = Cox-2 inhibitors; DMARD = disease-modifying antirheumatic drug; ICD-9-CM = International Classification of Diseases, Ninth Revision, Clinical Modification, } \\
\text { NSAIDs = nonsteroidal anti-inflammatory drugs; RA =rheumatoid arthritis; TNF= tumor necrosis factor. }\end{array}$} \\
\hline
\end{tabular}

Over $70 \%(72.1 \%)$ of the sample used nonbiologic DMARDs in the pre-index period, with methotrexate (58.2\%) being the most commonly prescribed nonbiologic DMARD. Forty-four percent of the matched sample received GCs in the pre-index period, and $77.9 \%$ of the sample used pain medications with narcotic analgesics $(53.2 \%)$ being the most commonly prescribed (53.2\%). The majority of the sample patients were on at least 2 nonstudy RA-related medications $(75.9 \%)$ and had a Charlson Comorbidity Index (CCI) score ranging from 1-2 (97.1\%) in the pre-index period. The CCI score often reflects the severity of the disease as well as the overall health status of the patient. Higher CCI scores indicate higher disease severity. Of the 4,149 total pre-index clinical visits, the majority $(84.1 \%)$ were for RA-related ambulatory and inpatient care (Table 4).

The index TNF inhibitor therapy was classified as effective using the claims-based algorithm in $15.7 \%$ of the study sample (12.4\%, 14.6\%, and $20.1 \%$, for ETN, ADA, and IFX, respectively). Overall, $74.7 \%$ of the sample had a low adherence to the 
TABLE 5 McNemar's Test Comparing Each Criterion of the Medication Effectiveness Algorithm Among TNF Inhibitors (Unadjusted Analysis)a

\begin{tabular}{|c|c|c|c|c|}
\hline Curtis Algorithm Criteria & ETN $(n=274)$ & ADA $(n=274)$ & Statistic & $P$ Value \\
\hline Adherence (MPR $\geq 80)(\%)$ & 16.4 & 21.2 & 2.1392 & 0.1766 \\
\hline No switching (\%) & 89.4 & 86.5 & 1.0323 & 0.3742 \\
\hline No additions of new nonbiologic DMARDs (\%) & 82.5 & 79.6 & 0.7619 & 0.4452 \\
\hline No increase in biologic dose or frequency (\%) & 98.2 & 88.7 & 19.8824 & $<0.0001^{b}$ \\
\hline No more than l GC joint injection (\%) & 99.3 & 98.9 & 0.2000 & 1.0000 \\
\hline No increase in dose of oral GC (\%) & 89.8 & 83.6 & 5.0702 & 0.0331 \\
\hline Effectiveness (\%) & 12.4 & 14.6 & 0.6667 & 0.4966 \\
\hline Curtis Algorithm Criteria & ETN $(n=274)$ & $\operatorname{IFX}(\mathbf{n}=274)$ & Statistic & $P$ Value \\
\hline Adherence (\%) & 16.4 & 38.3 & 30.5085 & $<0.0001^{b}$ \\
\hline No switching (\%) & 89.4 & 88.3 & 0.1636 & 0.7877 \\
\hline No additions of new nonbiologic DMARDs (\%) & 82.5 & 82.1 & 0.0141 & 1.0000 \\
\hline No increase in biologic dose or frequency (\%) & 98.2 & 80.3 & 40.6949 & $<0.0001^{b}$ \\
\hline No more than l GC joint injection (\%) & 99.3 & 97.1 & 3.6000 & 0.1094 \\
\hline No increase in dose of oral GC (\%) & 89.8 & 88.3 & 0.2963 & 0.6835 \\
\hline Effectiveness (\%) & 12.4 & 20.1 & 5.8800 & 0.0203 \\
\hline Curtis Algorithm Criteria & ADA $(n=274)$ & IFX $(\mathbf{n}=274)$ & Statistic & $P$ Value \\
\hline Adherence (\%) & 21.2 & 38.3 & 17.9593 & $<0.0001^{b}$ \\
\hline No switching (\%) & 86.5 & 88.3 & 0.4098 & 0.6089 \\
\hline No additions of new nonbiologic DMARDs (\%) & 79.6 & 82.1 & 0.6049 & 0.5052 \\
\hline No increase in biologic dose or frequency (\%) & 88.7 & 80.3 & 7.0533 & $0.0106^{\mathrm{b}}$ \\
\hline No more than 1 GC joint injection (\%) & 98.9 & 97.1 & 2.2727 & 0.2266 \\
\hline No increase in dose of oral GC (\%) & 83.6 & 88.3 & 2.6825 & 0.1299 \\
\hline Effectiveness (\%) & 14.6 & 20.1 & 2.5862 & 0.1329 \\
\hline \multicolumn{5}{|c|}{$\begin{array}{l}\text { Adapted from: Curtis JR, Baddley JW, Yang } S \text {, et al. Derivation and preliminary validation of an administrative claims-based algorithm for the effectiveness of medica } \\
\text { for rheumatoid arthritis. }{ }^{24} \\
{ }^{a} \mathrm{ADA} \text { and IFX were individually compared with ETN. Bonferroni correction was used to control for type } 1 \text { error due to multiple comparisons with a prior } P \text { value set } \\
0.0167(0.05 / n \text {, where } n=3 \text {, which is the number of comparisons). } \\
\text { bSignificant at } P<0.0167 \text {. } \\
\text { ADA = adalimumab; ETN =etanercept; DMARDs = disease-modifying antirheumatic drugs; GC=glucocorticoid; IFX=infliximab; MPR=medication possession ratio; } \\
\text { TNF= tumor necrosis factor. }\end{array}$} \\
\hline
\end{tabular}

index drug; $11.0 \%$ had a dose escalation; $11.9 \%$ had a switch from the index TNF inhibitor therapy to another biologic agent; 18.6\% had an addition of a new nonbiologic DMARD; $12.8 \%$ had an increase in concurrent oral glucocorticoid dose; and $1.6 \%$ had more than 1 GC joint injection (Table 5). The 3 treatment groups (ADA, ETN, and IFX) differed significantly for 2 of the 6 effectiveness criteria (medication adherence and dose escalation). A significantly higher proportion of patients on IFX were adherent compared with patients on ETN or ADA (38.3\% vs. $16.4 \%$ and $21.2 \%, P<0.0001$ for both). Adherence rates between ETN and ADA were not significantly different. A significantly higher proportion $(P<0.0001)$ of patients on ETN had no dose escalation compared with patients on ADA or IFX (98.2\% vs. $88.7 \%$ and $80.3 \%, P<0.0001$ ). Dose escalation rate was also significantly lower $(P=0.0106)$ for ADA compared with IFX. The multivariate conditional logistic regression analysis indicated no significant difference in overall effectiveness using the claims-based algorithm among the 3 TNF inhibitors nor any significant relationship between effectiveness and the study covariates (Table 6).

\section{Discussion}

This study estimated the effectiveness of ADA, ETN, and IFX among Texas Medicaid patients with RA using the Curtis et al. (2011) $)^{24}$ comparative effectiveness algorithm and found the algorithm-defined effectiveness to be comparable among the 3 TNF inhibitors. Demographic (age and gender distribution) and clinical characteristics of the final matched study sample were found to be consistent with those reported by other studies of patients with RA that were conducted using retrospective database analysis. ${ }^{2,4,28-42}$ However, in contrast to other studies where the majority of participants were white, the present study had a majority Hispanic population (53.7\%). ${ }^{31,32,36,37}$ This was expected, since Hispanics have been reported to account for a significant proportion $(\approx 40 \%)$ of the Texas population. ${ }^{43}$

The 2 main components of the effectiveness algorithm's criteria for which significant differences were found were dose escalation and adherence. Based on the study result, a significantly lower level of dose escalation was observed with ETN (1.8\%) compared with the use of ADA (11.3\%) and IFX (19.7\%). This result was not unexpected, since dose increases are described in the U.S. prescribing information for patients 
TABLE 6 Conditional Logistic Regression Analysis Comparing Likelihood of RA Medication Effectiveness Among TNF Inhibitors $(N=822)^{\text {a }}$

\begin{tabular}{|c|c|c|c|c|c|}
\hline & Odds Ratio & \multicolumn{2}{|c|}{$95 \% \mathrm{CI}$} & Wald $X^{2}$ & $P$ Value ${ }^{b}$ \\
\hline \multicolumn{6}{|l|}{ Medication type } \\
\hline Adalimumab vs. etanercept & 1.139 & 0.684 & 1.898 & 0.2510 & 0.6164 \\
\hline Infliximab vs. etanercept & 1.628 & 1.000 & 2.649 & 3.8399 & 0.0500 \\
\hline Adalimumab vs. infliximab & 0.700 & 0.439 & 1.117 & 2.2411 & 0.1344 \\
\hline \multicolumn{6}{|l|}{ Covariates } \\
\hline Age & 1.005 & 0.973 & 1.039 & 0.1099 & 0.7403 \\
\hline Male $^{\mathrm{c}}$ & 1.422 & 0.628 & 3.220 & 0.7110 & 0.3991 \\
\hline Nonwhites ${ }^{\mathrm{c}, \mathrm{d}}$ & 0.822 & 0.338 & 2.000 & 0.1868 & 0.6656 \\
\hline Pre-index DMARD nonuse ${ }^{c}$ & 1.029 & 0.167 & 6.337 & 0.0009 & 0.9755 \\
\hline Pre-index pain medications nonuse ${ }^{c}$ & 1.436 & 0.103 & 20.108 & 0.0721 & 0.7882 \\
\hline Pre-index glucocorticoids nonusec & 1.249 & 0.143 & 10.934 & 0.0404 & 0.8408 \\
\hline Pre-index RA-related visits & 1.033 & 0.624 & 1.711 & 0.0159 & 0.8998 \\
\hline Pre-index non-RA-related visits & 0.840 & 0.377 & 1.872 & 0.1825 & 0.6692 \\
\hline Total number of nonstudy RA-related medications & 1.136 & 0.509 & 2.537 & 0.0966 & 0.7559 \\
\hline Pre-index total utilization cost & 1.000 & 1.000 & 1.000 & 0.5580 & 0.4551 \\
\hline Charlson Comorbidity Index & 0.709 & 0.315 & 1.594 & 0.6936 & 0.4049 \\
\hline \multicolumn{6}{|c|}{ 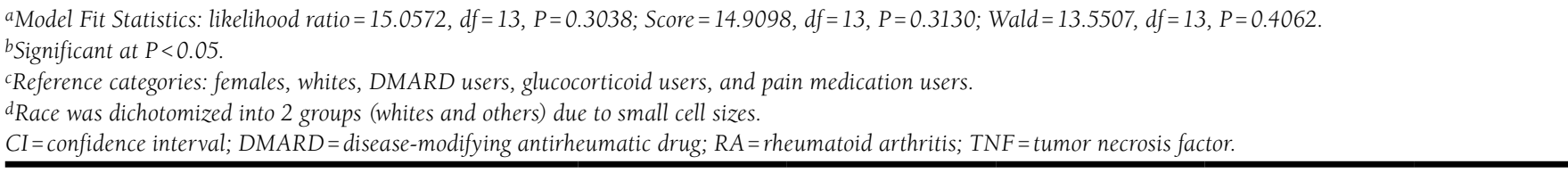 } \\
\hline
\end{tabular}

on ADA or IFX in situations of suboptimal treatment response but not for patients on ETN. ${ }^{18-20,44-47}$ Dose escalation patterns obtained in the present study were similar to those reported across a number of dose escalation studies with the proportion of patients having a dose escalation being consistently and significantly lower for ETN compared with ADA and IFX. ${ }^{28,29,34,35,37,39,40,42,48}$ Across all methods used to define dose escalation, the proportions ranged from $0.4 \%$ to $10.3 \%, 8.3 \%$ to $33.6 \%$, and $16.4 \%$ to $60 \%$ for ETN, ADA, and IFX, respectively. ${ }^{28,29,34,35,37,39,40,42,48}$

Overall, the proportion of adherent patients in the study sample was low $(\approx 25 \%)$ with significantly higher adherence shown with the use of IFX and comparable adherence observed between ETN and ADA. The direction of study results was comparable with those of earlier studies regardless of the method used for estimating adherence., 2,31,33,36 Differences in adherence may be a function of the route and frequency of administration. ${ }^{4}$ IFX is administered intravenously at the physician's office by a health care provider, while ETN and ADA are administered subcutaneously by the patient. IFX is infused at week 0,2 , and 6 and every 8 weeks thereafter, while ETN is given once weekly and ADA is administered once every other week. ${ }^{18-20}$ The patients on IFX may have adhered better because of appointment reminder messages that may have been sent by the clinic. However, the reasons responsible for the overall low level of adherence values is difficult to ascertain because other important information that impacts adherence (e.g., incidence of adverse events, lack of treatment response, and increased disability) were lacking in the administrative claims data used for this analysis.
Adherence seen in this study was lower than has been reported in previous adherence studies that also used administrative claims data (commercial or Medicaid). 2,30,31,36 This may be because of the high Hispanic population (53.7\%) in the study sample. Being of an ethnic minority has been associated with poor medication adherence. ${ }^{49}$ In addition, the study subjects were of low socioeconomic status (income and education), and subjects may have lacked adequate knowledge/understanding of their disease and its treatment. Other possible factors may include poor prior medication-taking behaviors and beliefs about medications. ${ }^{49}$ Clinicians caring for Medicaid patients need to be aware of these factors and should endeavor to work with each patient to identify patient-specific factors responsible for poor TNF-inhibitor therapy adherence. ${ }^{50}$ Reducing the impact of these factors and improving adherence should be included as a major part of the treatment plan for each RA patient.

\section{Limitations}

The present study is unique as it estimated effectiveness of ADA, ETN, and IFX among Medicaid RA patients using the 2011 Curtis et al. ${ }^{24}$ comparative effectiveness algorithm. However, the study has limitations that need to be considered when interpreting the study results. Administrative claims data are developed for the purpose of reimbursement rather than research. The presence of a claim for a TNF-inhibitor therapy (i.e., ETN or ADA) in the prescription claims data does not necessarily mean that the patient used the medication. However, for IFX, in the absence of fraudulent claims, the presence of an HCPCS J-code 1745 in the medical claims data indicates that it was infused. 
The nonrandomized distribution of the study groups and presence of baseline differences in clinical characteristics could introduce bias (i.e., selection bias) in the study results. Although PS matching and multivariate analyses were used to control for selection/channeling bias and confounding on known variables, there is the possibility that the study groups may still differ in unknown or unmeasured parameters that were not available in the dataset (e.g., disease activity and disability). In addition, the use of PS matching resulted in a significant decrease in the study sample size, causing a decrease in power. This may have been responsible for the inability to detect significant differences among study groups on some of the components of the effectiveness algorithm.

Due to the absence of unit of service information in the medical claims, cost information associated with HCPCS J-code 1745 was used as a proxy in assessing dose escalation for IFX. This may have either overestimated or underestimated dose escalation rates in this study group. The present study only analyzed 12 months of post-index data for biologic-naive patients. Study outcomes may differ if patients were followed for a longer time period, since RA is a chronic and progressive disease condition. Finally, the study sample had an over-representation of women, minorities (Hispanics), and people of lower socioeconomic status compared with the general U.S. population and thus cannot be generalized to other populations.

\section{Conclusion}

The study results suggest that when using a medication effectiveness algorithm, IFX, ETN, and ADA have comparable effectiveness in patients with RA. Patient adherence to therapy may be higher if given IFX, and patients who receive ETN are less likely to have a dose escalation.

\section{Authors}

ABIOLA OLADAPO, PhD, is Manager, Medical Outcomes Research $\&$ Economics, Baxter Healthcare Corporation, Westlake Village, California. JAMIE C. BARNER, PhD, is Professor of Health Outcomes \& Pharmacy Practice; KENNETH A. LAWSON, PhD, is Division Head and Professor of Health Outcomes \& Pharmacy Practice; SUZANNE NOVAK, MD, PhD, is Adjunct Faculty; KAREN L. RASCATI, PhD, is Professor of Health Outcomes E Pharmacy Practice; and KRISTIN M. RICHARDS, PhD, is Research Associate, Center for Pharmacoeconomic Studies, College of Pharmacy, The University of Texas at Austin. DAVID J. HARRISON, PhD, is Director, Global Health Economics, Amgen Inc., Thousand Oaks, California.

AUTHOR CORRESPONDENCE: Jamie C. Barner, PhD, Professor, Health Outcomes \& Pharmacy Practice, College of Pharmacy, The University of Texas at Austin, 2409 University Ave., STOP A1930, Austin, TX 78712-1120. Tel.: 512.471 .5612 (office);

Fax: 512.471.8762; E-mail: jbarner@austin.utexas.edu.

\section{DISCLOSURES}

Lawson, Novak, Rascati, and Richards indicated no conflict of interest regarding the content of this article. Oladapo and Barner received funding to conduct the study from Amgen, Inc. Harrison is an employee of Amgen, Inc. The final manuscript was reviewed by Amgen, Inc.

Oladapo and Barner collaborated on the conception of the project, study design, data analysis, and writing of the manuscript. Lawson, Novak, Rascati, Richards, and Harrison critically reviewed the study design, data analysis, results interpretation and contributed in the development and editing of the manuscript.

\section{ACKNOWLEDGMENTS}

The authors thank Texas Medicaid for the use of its data to conduct this study

\section{REFERENCES}

1. Punzi L, Matucci Cerinic M, Cantini F, et al. Treatment patterns of antiTNF agents in Italy: an observational study. Reumatismo. 2011;63(1):18-28 2. Borah BJ, Huang X, Zarotsky V, Globe D. Trends in RA patients' adherence to subcutaneous anti-TNF therapies and costs. Curr Med Res Opin. 2009;25(6):1365-77.

3. Centers for Disease Control and Prevention. Rheumatoid arthritis. 2011. Available at: http://www.cdc.gov/arthritis/basics/rheumatoid.htm. Accessed May 15, 2014

4. Tang B, Rahman M, Waters HC, Callegari P. Treatment persistence with adalimumab, etanercept, or infliximab in combination with methotrexate and the effects on health care costs in patients with rheumatoid arthritis. Clin Ther. 2008;30(7):1375-84.

5. Bathon JM, Martin RW, Fleischmann RM, et al. A comparison of etanercept and methotrexate in patients with early rheumatoid arthritis. N Engl J Med. 2000;343(22):1586-93.

6. Lipsky PE, van der Heijde DM, St Clair EW, et al. Infliximab and methotrexate in the treatment of rheumatoid arthritis. Anti-Tumor Necrosis Factor Trial in Rheumatoid Arthritis with Concomitant Therapy Study Group. N Engl J Med. 2000;343(22):1594-602.

7. Weinblatt ME, Keystone EC, Furst DE, et al. Adalimumab, a fully human anti-tumor necrosis factor alpha monoclonal antibody, for the treatment of rheumatoid arthritis in patients taking concomitant methotrexate: the ARMADA trial. Arthritis Rheum. 2003;48(1):35-45.

8. Kay J, Matteson EL, Dasgupta B, et al. Golimumab in patients with active rheumatoid arthritis despite treatment with methotrexate: a randomized, double-blind, placebo-controlled, dose-ranging study. Arthritis Rheum. 2008;58(4):964-75

9. Smolen J, Landewe RB, Mease P, et al. Efficacy and safety of certolizumab pegol plus methotrexate in active rheumatoid arthritis: the RAPID 2 study. A randomised controlled trial. Ann Rheum Dis. 2009;68(6):797-804.

10. Breedveld FC, Weisman MH, Kavanaugh AF, et al. The PREMIER study: A multicenter, randomized, double-blind clinical trial of combination therapy with adalimumab plus methotrexate versus methotrexate alone or adalimumab alone in patients with early, aggressive rheumatoid arthritis who had not had previous methotrexate treatment. Arthritis Rheum. 2006;54(1):26-37.

11. van der Heijde D, Klareskog L, Rodriguez-Valverde V, et al. Comparison of etanercept and methotrexate, alone and combined, in the treatment of rheumatoid arthritis: two-year clinical and radiographic results from the TEMPO study, a double-blind, randomized trial. Arthritis Rheum. 2006;54(4):1063-74.

12. Gartlehner G, Hansen RA, Jonas BL, Thieda P, Lohr KN. The comparative efficacy and safety of biologics for the treatment of rheumatoid arthritis: a systematic review and metaanalysis. J Rheumatol. 2006;33(12):2398-408. 13. Hochberg MC, Tracy JK, Hawkins-Holt M, Flores RH. Comparison of the efficacy of the tumour necrosis factor alpha blocking agents adalimum$a b$, etanercept, and infliximab when added to methotrexate in patients with active rheumatoid arthritis. Ann Rheum Dis. 2003;62(Suppl 2):iil3-16.

14. Lee YH, Woo JH, Rho YH, Choi SJ, Ji JD, Song GG. Meta-analysis of the combination of TNF inhibitors plus MTX compared to MTX monotherapy, and the adjusted indirect comparison of TNF inhibitors in patients suffering from active rheumatoid arthritis. Rheumatol Int. 2008;28(6):553-59. 


\section{Medication Effectiveness with the Use of Tumor Necrosis Factor Inhibitors Among Texas Medicaid Patients Diagnosed with Rheumatoid Arthritis}

15. Kristensen LE, Christensen R, Bliddal H, Geborek P, DanneskioldSamsøe B, Saxne T. The number needed to treat for adalimumab, etanercept, and infliximab based on ACR50 response in three randomized controlled trials on established rheumatoid arthritis: a systematic literature review. Scand J Rheumatol. 2007;36(6):411-17.

16. Donahue KE, Gartlehner G, Jonas DE, et al. Systematic review: comparative effectiveness and harms of disease-modifying medications for rheumatoid arthritis. Ann Intern Med. 2008;148(2):124-34.

17. Wiens A, Venson R, Correr CJ, Otuki MF, Pontarolo R. Meta-analysis of the efficacy and safety of adalimumab, etanercept, and infliximab for the treatment of rheumatoid arthritis. Pharmacotherapy. 2010;30(4):339-53. 18. U.S. Food and Drug Administration. HUMIRA (adalimumab) product approval information. Licensing action (label). Abbott Laboratories. December 2002. Available at: http://www.fda.gov/downloads/Drugs/ DevelopmentApprovalProcess/HowDrugsareDevelopedandApproved/ ApprovalApplications/TherapeuticBiologicApplications/ucm092762.pdf. Accessed May 15, 2014.

19. U.S. Food and Drug Administration. REMICADE (infliximab) product approval information. Licensing action (label). Centocor Inc. February 2002. Available at: http://www.fda.gov/downloads/Drugs/ DevelopmentApprovalProcess/HowDrugsareDevelopedandApproved/ ApprovalApplications/TherapeuticBiologicApplications/ucml07713.pdf. Accessed May 15, 2014.

20. U.S. Food and Drug Administration. ENBREL (etanercept) product approval information. Licensing action (label). Amgen and Wyeth Pharmaceuticals. June 2003. Available at: http://www.fda.gov/downloads/ Drugs/DevelopmentApprovalProcess/HowDrugsareDevelopedandApproved/ ApprovalApplications/TherapeuticBiologicApplications/ucm088826.pdf. Accessed May 15, 2014.

21. Curtis JR, Jain A, Askling J, et al. A comparison of patient characteristics and outcomes in selected European and U.S. rheumatoid arthritis registries. Semin Arthritis Rheum. 2010;40(1):2-14.

22. Schneeweiss S, Avorn J. A review of uses of health care utilization databases for epidemiologic research on therapeutics. J Clin Epidemiol. 2005;58(4):323-27.

23. Kim S, Servi A, Polinski J, et al. Validation of rheumatoid arthritis diagnoses in health care utilization data. Arthritis Res Ther. 2011;13(1):R32. 24. Curtis JR, Baddley JW, Yang S, et al. Derivation and preliminary validation of an administrative claims-based algorithm for the effectiveness of medications for rheumatoid arthritis. Arthritis Res Ther. 2011;13(5):R155. 25. Curtis JR, Chastek B, Becker L, et al. Further evaluation of a claimsbased algorithm to determine the effectiveness of biologics for rheumatoid arthritis using commercial claims data. Arthritis Res Ther. 2013;15(2):404. 26. Austin PC. A critical appraisal of propensity-score matching in the medical literature between 1996 and 2003. Stat Med. 2008;27(12):2037-49.

27. Rassen JA, Shelat AA, Franklin JM, Glynn RJ, Solomon DH, Schneeweiss S. Matching by propensity score in cohort studies with three treatment groups Epidemiology. 2013;24(3):401-09.

28. Wu E, Chen L, Birnbaum H, Yang E, Cifaldi M. Retrospective claims data analysis of dosage adjustment patterns of TNF antagonists among patients with rheumatoid arthritis. Curr Med Res Opin. 2008;24(8):2229-40. 29. Bonafede MM, Gandra SR, Fox KM, Wilson KL. Tumor necrosis factor blocker dose escalation among biologic naïve rheumatoid arthritis patients in commercial managed-care plans in the 2 years following therapy initiation. J Med Econ. 2012;15(4):635-43.

30. Curkendall S, Patel V, Gleeson M, Campbell RS, Zagari M, Dubois R. Compliance with biologic therapies for rheumatoid arthritis: do patient outof-pocket payments matter? Arthritis Rheum. 2008;59(10):1519-26.

31. Grijalva CG, Chung CP, Arbogast PG, Stein CM, Mitchel EF Jr, Griffin MR. Assessment of adherence to and persistence on disease-modifying antirheumatic drugs (DMARDs) in patients with rheumatoid arthritis. Med Care. 2007;45(10 Suppl 2):S66-S76.

32. Grijalva CG, Kaltenbach L, Arbogast PG, Mitchel EF Jr, Griffin MR Adherence to disease modifying anti-rheumatic drugs and the effects of exposure misclassification on the risk of hospital admission. Arthritis Care Res (Hoboken). 2010;62(5):730-34

33. Harley CR, Frytak JR, Tandon N. Treatment compliance and dosage administration among rheumatoid arthritis patients receiving infliximab, etanercept, or methotrexate. Am J Manag Care. 2003;9(6 Suppl):S136-S43.
34. Harrison DJ, Huang X, Globe D. Dosing patterns and costs of tumor necrosis factor inhibitor use for rheumatoid arthritis. Am J Health Syst Pharm. 2010;67(15):1281-87.

35. Huang X, Gu NY, Fox KM, Harrison DJ, Globe D. Comparison of methods for measuring dose escalation of the subcutaneous TNF antagonists for rheumatoid arthritis patients treated in routine clinical practice. Curr Med Res Opin. 2010;26(7):1637-45.

36. Li P, Blum MA, Von Feldt J, Hennessy S, Doshi JA. Adherence, discontinuation, and switching of biologic therapies in medicaid enrollees with rheumatoid arthritis. Value Health. 2010;13(6):805-12.

37. Schabert VF, Bruce B, Ferrufino CF, et al. Disability outcomes and dose escalation with etanercept, adalimumab, and infliximab in rheumatoid arthritis patients: a US-based retrospective comparative effectiveness study. Curr Med Res Opin. 2012;28(4):569-80.

38. Yazici Y, Krasnokutsky S, Barnes JP, Hines PL, Wang J, Rosenblatt L. Changing patterns of tumor necrosis factor inhibitor use in 9074 patients with rheumatoid arthritis. J Rheumatol. 2009;36(5):907-13.

39. Gu N, Huang X, Fox K, Patel V, Baumgartner S, Chiou C. Claims data analysis of dosing and cost of TNF antagonists. Am J Pharm Benefits. 2010;2(6):351-59.

40. Fisher MD, Watson C, Fox KM, Chen YW, Gandra SR. Dosing patterns of three tumor necrosis factor blockers among patients with rheumatoid arthritis in a large United States managed care population. Curr Med Res Opin. 2013;29(5):561-68.

41. Carter CT, Changolkar AK, Scott McKenzie R. Adalimumab, etanercept, and infliximab utilization patterns and drug costs among rheumatoid arthritis patients. J Med Econ. 2012;15(2):332-39.

42. Ollendorf DA, Klingman D, Hazard E, Ray S. Differences in annual medication costs and rates of dosage increase between tumor necrosis factorantagonist therapies for rheumatoid arthritis in a managed care population. Clin Ther. 2009;31(4):825-35.

43. The Henry J. Kaiser Family Foundation. Population distribution by race/ ethnicity. 2013. Available at: http://kff.org/other/state-indicator/distributionby-raceethnicity/?state=TX. Accessed May 16, 2014.

44. Ariza-Ariza R, Navarro-Sarabia F, Hernández-Cruz B, RodríguezArboleya L, Navarro-Compán V, Toyos J. Dose escalation of the anti-TNFalpha agents in patients with rheumatoid arthritis. A systematic review. Rheumatology (Oxford). 2007;46(3):529-32.

45. Moots RJ, Haraoui B, Matucci-Cerinic M, et al. Differences in biologic dose-escalation, non-biologic and steroid intensification among three anti-TNF agents: evidence from clinical practice. Clin Exp Rheumatol. 2011;29(1):26-34

46. Rahman MU, Strusberg I, Geusens P, et al. Double-blinded infliximab dose escalation in patients with rheumatoid arthritis. Ann Rheum Dis. 2007;66(9):1233-38.

47. Weinblatt ME, Schiff MH, Ruderman EM, et al. Efficacy and safety of etanercept $50 \mathrm{mg}$ twice a week in patients with rheumatoid arthritis who had a suboptimal response to etanercept $50 \mathrm{mg}$ once a week: results of a multicenter, randomized, double-blind, active drug-controlled study. Arthritis Rheum. 2008;58(7):1921-30.

48. Blume SW, Fox KM, Joseph G, Chuang CC, Thomas J, Gandra SR. Tumor necrosis factor-blocker dose escalation in rheumatoid arthritis patients in a pharmacy benefit management setting. Adv Ther. 2013;30(5):517-27.

49. Pascual-Ramos V, Contreras-Yáñez I, Villa AR, Cabiedes J, Rull-Gabayet M. Medication persistence over 2 years of follow-up in a cohort of early rheumatoid arthritis patients: associated factors and relationship with disease activity and with disability. Arthritis Res Ther. 2009;11(1):R26.

50. van den Bemt BJ, van den Hoogen FH, Benraad B, Hekster YA, van Riel $\mathrm{PL}$, van Lankveld W. Adherence rates and associations with nonadherence in patients with rheumatoid arthritis using disease modifying antirheumatic drugs. J Rheumatol. 2009;36(10):2164-70.

51. Rassen JA, Doherty M, Huang W, Schneeweiss S. Pharmacoepidemiology toolbox. Brigham and Women's Hospital Department of Medicine. Available at: http://www.drugepi.org/dope-downloads/\#Pharmacoepidemiology Toolbox. Accessed May 16, 2014 